\title{
How Different Knee Flexion Angles Influence the Hip Extensor in the Prone Position
}

\author{
Yu-JeOng Kwon, MS, PT ${ }^{1)}$, Hyun-OK Lee, PhD, PT ${ }^{1)^{*}}$ \\ 1) Department of Physical Therapy, College of Health Sciences, Catholic University of Pusan: Bugok \\ 3-dong, Geumjung-gu, Busan 609-757, Republic of Korea
}

\begin{abstract}
Purpose] The present study examined the effects of knee flexion angle on hip extensor muscle activity. [Subjects and Methods] Twenty healthy subjects maintained knee flexion angles of $0^{\circ}, 30^{\circ}, 60^{\circ}, 90^{\circ}$ and $110^{\circ}$ in the prone position and performed maximal voluntary contraction in hip extension. Maximum torque in hip extension at the different angles was measured, and surface electromyogram activities of the gluteus maximus (GM), biceps femoris (BF) and semitendinosus (ST) were recorded and normalized by the maximum voluntary isometric contraction (MVIC). [Results] The maximum torque of the hip extensor showed significant decreases between $0^{\circ}$ and $60^{\circ}$, $90^{\circ}$ and $110^{\circ}$ of knee flexion. The muscle activity of BF was significantly high at $0^{\circ}$, and GM showed a significantly higher activity than both $\mathrm{BF}$ and ST at $60^{\circ}, 90^{\circ}$ and $110^{\circ}$ of knee flexion. [Conclusion] The maximum torque in hip extension and muscle activities of BF and ST were significantly high at $0^{\circ}$ but they decreased at knee flexion angles of more than $60^{\circ}$. Therefore, we consider that more than $60^{\circ}$ of knee joint flexion is required to increase GM activity, and to reduce the muscle activities of BF and ST.
\end{abstract}

Key words: Gluteus maximus, Hamstring muscle, Prone hip extension

(This article was submitted Apr. 1, 2013, and was accepted May 29, 2013)

\section{INTRODUCTION}

The gluteus maximus (GM) prevents the hip, knee and ankle from collapsing in the early stance phase of gait, creating most of the supporting power and providing stability to the sacroiliac joint (SI joint) ${ }^{1)}$. If the GM works inappropriately during gait, it can cause back pain, resulting from a lack of shock-absorption at the sacroiliac joint ${ }^{2)}$, and Hungerford et al. ${ }^{3)}$ suggested that the activity of GM in the legs of patients with sacroiliac joint pain is delayed, and that the biceps femoris shows early activation to compensate for this delay. Moreover, individuals with limited movement of GM show fast movement of the hamstring muscles (HAM) and erector spinae muscles for better stability of their back ${ }^{4}$, 5). In some studies of back pain, it has been reported the activity pattern of GM was limited in functional activity or in exercise, or that it shows overactivity ${ }^{6-8)}$. GM and HAM are synergists of hip extension, and a properly controlled pattern is required, since they are involved in stability and movement of the joint. Thus, assessment and controlled exercise for these muscles must be performed accurately. Especially, since HAM is a muscle connecting two joints, its effects on hip extension at different knee joint flexion angles should be considered.

Commonly, the manual muscle test of hip extension is performed in prone hip extension with knee extension.

In particular, for the isolation test of GM, hip extension is initiated with knee flexion of $90^{\circ}$.

${ }^{*}$ To whom correspondence should be addressed.

E-mail: holee@cup.ac.kr
This position is mainly used for the muscle test or muscle strengthening exercises in clinical practice, because it is practical to assess the activity of GM, since is difficult for the hamstring muscle to exert power due to insufficient activity $^{9-11)}$.

However, there have been few studies on changing of two muscles activities at different angles of knee flexion.

Therefore, the purpose of this study was to identify the effects of knee joint flexion angle on hip extensor muscle activity.

\section{SUBJECTS AND METHODS}

Twenty adults men and women were given an explanation about the purpose and procedures of this study before they voluntarily agreed to participate. Only those without pathological issues related to the knee joint, hip joint and back were selected as subjects for the study (age: $22.9 \pm 2.4$ years [mean \pm SD]; height: $170.8 \pm 6.45 \mathrm{~cm}$; weight: $65.9 \pm 10.97 \mathrm{~kg}$ ).

Subjects adopted a prone position with both their arms at the sides of the trunk. They maintained the dominant knee at angles of $0^{\circ}, 30^{\circ}, 60^{\circ}, 110^{\circ}$, and performed maximal voluntary contraction of hip extension. At this time, they were not allowed to twist or extend their back and compensation (such as pushing the bed with the arms) was prohibited. Both the knee joint flexion angle and hip extensor angle were measured with a Myrin goniometer (Norway).

Maximum torque at each of the knee angles was measured by measuring maximum power using a Commander ${ }^{\mathrm{TM}}$ Muscle Tester (Jtech Medical Ind., Salt Lake City, UT, USA), placed $15 \mathrm{~cm}$ above the knee joint. The maximum torque was calculated as maximum power multiplied by 
the distance from the greater trochanter to $15 \mathrm{~cm}$ above the knee joint. Three measurements at each knee angle were performed. Each measurement lasted for 5 seconds, and was followed by 30 seconds of rest time. After completion of measurements at each angle, 1 minute's test was given.

A surface electromyography system (Noraxon TeleMyo DTS Telemetry) was used to record the activities of the GM and HAM muscles. The recorded EMGs were processed using a personal computer and MyoRearch XP 1.06 Master Edition software. The activities of both GM and HAM were recorded by surface electrodes, following the recommendations of SENIAM ${ }^{12)}$ and ISEK $^{13)}$ for skin preparation and electrode position. To minimize the impedance of the skin, hair was shaved and the electrode site was cleaned with alcohol on a cotton swab. To measure muscle activity, subjects adopted a prone position with their dominant knee maintained at one of the flexion angles. The hip joint was extended at $20^{\circ}$, and resistance was provided for the performance of maximum voluntary contraction for $5 \mathrm{sec}-$ onds. The first and the last 1 second of each recording was discarded and the middle 3 seconds were converted to root mean square (RMS) values and normalized to \%MVIC of each muscle, before performing the comparative analysis.

Data were processed using SPSS 18 for Windows. To compare the maximum torque and muscle activation of the GM, biceps femoris (BF) and semitendinosus (ST) at the five different knee joint flexion angles, one-way ANOVA was used. To identify differences for each muscle, Bonferroni's post-hoc test was performed. Statistical significance was accepted for values of $p<0.05$.

\section{RESULTS}

Maximum torque of the hip extensor showed significant differences among the knee flexion angles $(p<0.05)$, and tended to increase as the angle increased (Table 1).

The activities of the hip extensor at each knee flexion angle showed significant differences (Table 2). When the angle was $0^{\circ}$, only the biceps femoris activity was high. GM activity significantly increased only when the knee flexion angle was more than $60^{\circ}$ (Table2).

\section{DISCUSSION}

In this study we gradually shortened the length of hamstring muscle by increasing the knee joint flexion angle of from $0^{\circ}$, to $30^{\circ}, 60^{\circ}, 90^{\circ}, 110^{\circ}$. The length of $\mathrm{GM}$ is not alternated at hip extension angle of $20^{\circ}$.

The hip extensors showed a significant decrease between $0^{\circ}$ and $60^{\circ}$ flexion of the knee. This corresponds with the results of a previous study ${ }^{14)}$, which investigated the torque of knee flexion at different hip flexion angles. Hip extension torque decreased due to the decrease in HAM length, when knee flexion was greater than $60^{\circ}$. Increased torque of a lengthened muscle is the result of the two causes. First, when connective tissue (which is a non-contractile factor) is extended, it creates passive tension and it helps to create active tension by muscle contraction. Shortened length relaxes these passive factors. Thus, as the level of relaxation increases, the tension decreases. The second cause is the efficiency of muscle contraction, and it can be explained Huxley's sliding filament model (relationship between length and tension) ${ }^{15)}$. This model, states that the highest tension is created in the optimal position, where actin and myosin fibers overlap the most. If the muscle is shorter or longer than the optimal length, the actin-myosin combination is weakened and its tension is decreased. Therefore, in the present study, hip extension torque decreased, because the HAM muscle length was shortened at more than $60^{\circ}$ of knee flexion.

In hip extension at $0^{\circ}$ of knee flexion, HAM activity was significantly greater than that of GM. HAM and GM showed no significant difference at $30^{\circ}$ of knee flexion. At $60^{\circ}$ of knee flexion, however, GM activity was significantly

Table 1. Comparison of the hip extensor torque during prone hip extension at different knee flexion angles

\begin{tabular}{cccccc}
\hline & \multicolumn{5}{c}{ Mean \pm SD } \\
\cline { 2 - 6 } & $0^{\circ}$ & $30^{\circ}$ & $60^{\circ}$ & $90^{\circ}$ & $110^{\circ}$ \\
\hline Torque $(\mathrm{kg} \cdot \mathrm{m})$ & $4.52^{\mathrm{a}} \pm 1.41$ & $3.75^{\mathrm{a}} \pm 1.43$ & $3.16^{\mathrm{b}} \pm 1.39$ & $2.82^{\mathrm{b}} \pm 1.19$ & $2.45^{\mathrm{b}} \pm 0.97$ \\
\hline
\end{tabular}

${ }^{a, b}$ Different superscripts indicate significant differences $(p<0.05)$.

Table 2. Hip extensor activation during prone hip extension at different knee flexion angles

\begin{tabular}{cccc}
\hline & \multicolumn{3}{c}{ Mean \pm SD $(\%$ MVIC $)$} \\
\cline { 2 - 4 } & GM & BF & ST \\
\hline $0^{\circ}$ & $48.14 \pm 16.65^{\mathrm{a}}$ & $73.95 \pm 26.05$ & $50.90 \pm 25.00^{\mathrm{a}}$ \\
$30^{\circ}$ & $53.48 \pm 17.53$ & $65.03 \pm 25.92$ & $42.62 \pm 20.14^{\mathrm{a}}$ \\
$60^{\circ}$ & $62.36 \pm 15.26$ & $44.88 \pm 20.71^{\mathrm{a}}$ & $33.98 \pm 14.36^{\mathrm{a}}$ \\
$90^{\circ}$ & $65.11 \pm 19.00$ & $36.05 \pm 15.75^{\mathrm{a}}$ & $30.35 \pm 12.58^{\mathrm{a}}$ \\
$110^{\circ}$ & $63.27 \pm 19.35$ & $32.78 \pm 14.5^{\mathrm{a}}$ & $30.17 \pm 12.48^{\mathrm{a}}$ \\
\hline
\end{tabular}

GM: Gluteus Maximus, BF: Biceps femoris, ST: Semitendinosus, ${ }^{\text {STuperscripts }}$ within the same column indicate significant differences $(p<0.05)$. 
higher than that of HAM. However, at $60^{\circ}, 90^{\circ}$ and $110^{\circ}$ of knee flexion, there were no big differences in GM activity. Many researchers have studied the difference in muscle activity at different HAM muscle lengths, and most of them compared activities at different angles of knee flexion ${ }^{14}$.

Kennedy and Cresswell studied the activity of the gastrocnemius in plantarflexion at different knee flexion angles. They reported results similar to those of the present study, that the RMS value of the gastrocnemius was significantly decreased when the gastrocnemius length was shortened as knee flexion angles increased ${ }^{16)}$. Thus, in two joint muscles, when one joint is fixed as the muscle is shortened by the other joint performing a movement, the number of muscle fibers used for the movement is considered to be decreased. This corresponds with the change of torque explained previously. In the present study, as knee flexion increased, the activity of HAM muscle decreased, thus, the torque of the hip extensor likely decreased. GM activity induced by knee flexion is also likely to be increased as the knee flexion angle increases. Especially, at knee flexion angles of more than $60^{\circ}$, more muscle fibers are used for hip extension than for HAM, because GM does not change its length at different angles, since it is a one-joint muscle. Nevertheless, the use of muscle fibers in GM increased due to the decreased activity of HAM as a result of the increase in knee flexion.

A limitation of the present study was that we failed to control for the effect of hip rotation and extension angle on the hip extensor, because the angle for hip extension was initiated at the small angle of $20^{\circ}$ in the neutral position. Therefore, further study of hip extensor with hip rotation and extension is needed.

In conclusion, maximum torque of hip extensor and HAM activation were significantly higher at $0^{\circ}$ of knee flexion than at knee flexion angles of more than $60^{\circ}$. GM activation increased at knee flexion angles of more than $60^{\circ}$. Therefore, to selectively test GM and HAM, we suggest that tests be performed at more than $60^{\circ}$ of knee flexion.

\section{REFERENCES}

1) Lieberman DE, Raichlen DA, Pontzer H, et al.: The human gluteus maximus and its role in running. J Exp Biol, 2006, 209: 2143-2155. [Medline] [CrossRef]

2) Hossain M, Nokes LD: A model of dynamic sacro-iliac joint instability from malrecruitment of gluteus maximus and biceps femoris muscles resulting in low back pain. Med Hypotheses, 2005, 65: 278-281. [Medline] [CrossRef]

3) Hungerford B, Gilleard W, Hodges P: Evidence of altered lumbopelvic muscle recruitment in the presence of sacroiliac joint pain. Spine, 2003, 28: 1593-1600. [Medline] [CrossRef]

4) Sahrmann SA: Diagnosis and treatment of movement impairment syndromes, 1st ed. St Louis: Mosby, 2002.

5) Vogt L, Banzer W: Dynamic testing of the motor stereotype in prone hip extension from neutral position. Clin Biomech (Bristol, Avon), 1997, 12: 122-127. [Medline] [CrossRef]

6) Leinonen V, Kankaanpaa M, Airaksinen O, et al.: Back and hip extensor activities during trunk flexion/extension: effects of low back pain and rehabilitation. Arch Phys Med Rehabil, 2000, 81: 32-37. [Medline]

7) Mooney V, Pozos R, Vleeming A, et al.: Exercise treatment for sacroiliac pain. Orthopedics, 2001, 24: 29-32. [Medline]

8) Vogt L, Pfeifer K, Banzer W: Neuromuscular control of walking with chronic low-back pain. Man Ther, 2003, 8: 21-28. [Medline] [CrossRef]

9) Wilson J, Ferris E, Heckler A, et al.: A structured review of the role of gluteus maximus in rehabilitation. N Z J Physiotherapy, 2004, 33: 95-100.

10) Distefano LJ, Blackburn JT, Marshall SW, et al.: Gluteal muscle activation during common therapeutic exercises. J Orthop Sports Phys Ther, 2009, 39: 532-540. [Medline]

11) Sakamoto AC, Teixeira-Salmela L, de Paula-Goulart F, et al.: Muscular activation patterns during active prone hip extension exercises. J Electromyogr Kinesiol, 2009, 19: 105-112. [Medline] [CrossRef]

12) Hermens HJ, Freriks B, Merletti R, et al.: SENIAM 8: European recommendations for surface electromyography, deliverable of the SENIAM project. Enschede: Roessingh Research and Development, 1999.

13) Merletti R, Tonio P: Standards for reporting EMG data. J Electromyogr Kinesiol, 1999, 9: 3-5.

14) Mohamed O, Perry J, Hislop H: Relationship between wire EMG activity, muscle length, and torque of the hamstring. Clin Biomech (Bristol, Avon), 2002, 17: 569-579. [Medline] [CrossRef]

15) Huxley AF: The activation of striated muscle and its mechanical response. Proc R Soc Lond B Biol Sci, 1971, 178: 1-27. [Medline] [CrossRef]

16) Kennedy PM, Cresswell AG: The effect of muscle length on motor-unit recruitment during isometric plantar flexion in humans. Exp Brain Res, 2001, 137: 58-64. [Medline] [CrossRef] 